\title{
Frequency of Instructor- and Student-Centered Teaching Practices in Introductory CS Courses
}

\author{
Christopher Lynnly Hovey \\ University of Colorado Boulder \\ Boulder, CO USA \\ hoveyc@colorado.edu
}

\author{
Lecia Barker \\ University of Colorado Boulder \\ Boulder, CO USA \\ barkerl@colorado.edu
}

\author{
Margaret Luebs \\ University of Colorado Boulder \\ Boulder, CO USA \\ margaret.luebs@colorado.edu
}

\begin{abstract}
Despite growing promotion of student-centered teaching, few studies have assessed how widely these practices have diffused throughout computer science (CS) higher education. Studies on teaching practices often treat instructor- and student-centered learning as being dichotomous. Recent research indicates that this reductionist model misinterprets what actually goes on in CS classrooms. For example, a recent study found that most CS faculty categorized their teaching practices as equally studentcentered and instructor-centered. We contribute to this scholarship by reporting the results of a survey disseminated to 821 CS educators in 595 universities, colleges, and community colleges in the U.S. Participants were asked to report how frequently they employed several instructor- or student-centered teaching practices and tools during the most recent semester that they taught a specific course. Results indicate that when asked to reflect on specific behaviors within a certain timeframe, faculty reported using instructor-centered teaching practices, especially delivering content via lecture, more than student-centered practices. However, most faculty also reported using at least one student-centered technique, albeit less frequently, throughout the semester. This study found few differences across certain situational and demographic variables (e.g., institution type, tenure status, etc.). Faculty justify their teaching choices with concern for negative evaluations, desire for student learning, large enrollments, heavy teaching loads, and retaining underrepresented students.
\end{abstract}

\section{CCS CONCEPTS}

- Social and professional topics $\sim$ Computing education

\section{KEYWORDS}

undergraduate computing education; lecturing; instructional techniques and strategies; student-centered teaching; evidencebased practices; faculty adoption; signature pedagogies

Permission to make digital or hard copies of all or part of this work for personal or classroom use is granted without fee provided that copies are not made or distributed for profit or commercial advantage and that copies bear this notice and the full citation on the first page. Copyrights for components of this work owned by others than ACM must be honored. Abstracting with credit is permitted. To copy otherwise, or republish, to post on servers or to redistribute to lists, requires prior specific permission and/or a fee. Request permissions from Permissions@acm.org. SIGCSE '19, February 27-March 2, 2019, Minneapolis, MN, USA

(c) 2019 Association for Computing Machinery.

ACM ISBN 978-1-4503-5890-3/19/02 ...\$15.00

https://doi.org/10.1145/3287324.3287363
ACM Reference format:

Christopher Lynnly Hovey, Lecia Barker, and Margaret Luebs. 2019. Frequency of Instructor- and Student-Centered Teaching Practices in Introductory CS Courses. In Proceedings of the 50th ACM Technical Symposium on Computer Science Education (SIGCSE '19), February 27March 2, 2019, Minneapolis, MN, USA. 7 pages. https://doi.org/10.1145/3287324.3287363

\section{INTRODUCTION}

Despite the attention that funding agencies, educational specialists, social scientists, and computer science (CS) faculty have given to developing and propagating active, studentcentered teaching practices, few studies have assessed how well these practices have diffused throughout CS higher education. Student-centered practices are promoted for good reason. A recent meta-analysis of 225 empirical studies provides strong evidence that active learning approaches improve students' performance [11]. Student-centered teaching practices early in the curriculum have also been shown to positively impact undergraduates' decisions to declare and remain in a major [6, 23]. Studies in other STEM fields suggest that instructorcentered teaching is still the most predominant approach $[8,15]$, but these studies often dichotomize instructor- and studentcentered learning, describing faculty's instructional proclivities as falling squarely into only one category.

Recent research in CS education suggests that this dichotomous model may misinterpret what actually goes on in CS classrooms. Grissom, et al. [12] used the Postsecondary Instructional Practices Survey (PIPS) [28] to gauge the teaching practices of 365 CS faculty from 45 U.S. and one Canadian institution. The PIPS asks faculty to rate teaching practices on two independent scales of instructor- and student-centered instructional practices. Practices are rated based on the degree to which the respondent believes they are "descriptive of their teaching." The PIPS was piloted at four institutions to develop the instructor-centered and student-centered scales used by [12]. According to the pilot [28], the 15-item student-centered scale had high reliability $(\alpha=.877)$, and the 9-item instructor-centered scale had lower reliability $(\alpha=.677)$. In Grissom et al.'s use of PIPS among CS faculty, CS faculty were equally likely to describe their teaching practices as student-centered and instructorcentered. However, the survey did not report on the use frequency of instructor- and student-centered practices, so it is not clear what specific practices were most commonly selected.

We contribute to this growing body of scholarship by reporting the results of a survey taken by 821 post-secondary CS educators in 595 diverse institutions. The survey was grounded 
in interviews and classroom observations with CS faculty in every region and institution type in the U.S. Participants were asked to think about a specific course they had recently taught, and then report how frequently they had employed several teaching practices and tools. Our results indicate that when primed to think about concrete teaching practices in the context of a specific course, faculty reported using instructor-centered teaching practices-especially delivering content via lecturemore frequently than student-centered practices. However, consistent with [12], most faculty reported using both instructorand student-centered practices, rarely just one or the other.

In the next section, we briefly review scholarship on studentand instructor-centered teaching practices, followed by a description of our research methods and sample profile. Then, we present results, including differences in the selection of certain teaching practices by different groups of faculty by institutional type, tenure status, and gender. We then describe respondents' unsolicited justifications for their teaching choices. We conclude by summarizing and discussing the findings.

\section{STUDENT- AND INSTRUCTOR-CENTERED TEACHING}

Student-centered teaching practices are curricular, pedagogical, or administrative techniques intended to increase interactivity among students and their peers, instructors, and the material in a way that privileges students' experiences, identities, intellectual growth, and personal development [18]. In CS, these practices include a broad range of instructional techniques such as pair programming and flipping the classroom, and teaching strategies such as emphasizing collaborative teamwork in or out of class.

Instructor-centered practices emphasize one-way information delivery from the educator, as the locus of knowledge, to a more or less passive audience of students, who act as receptacles of information. Knowledge is often communicated to students as a set of established formulas that they must accumulate and master, which are assessed against a preset standard [4, 13, 14]. Some scholars (e.g., [18]) have even argued that the goal of instructor-centered techniques is to produce homogenized, interchangeable workers for the industrialized workforce.

In our current era of post-industrial globalism [7, 22], it is clear that the education system must evolve to produce a diverse workforce of innovative, creative workers who can address the complex and dynamic needs of the (post)modern economy [20, 21]. Student-centered teaching practices have been shown to produce the following benefits:

Benefits for Student Performance. A recent, often-cited metaanalysis of 225 empirical studies across STEM fields provides strong evidence that active learning approaches improve students' performance [11]. A study focused specifically on CS classes also found that student-centered approaches greatly improved student performance [24].

Benefits for Student Engagement. Student-centered teaching practices have been shown to greatly increase student engagement in college science classes [25].

Benefits for Student Retention. The use of student-centered teaching practices, especially early in the curriculum, can positively impact undergraduates' decisions to declare a major and remain in that major $[6,23]$.
Benefits for Diversity. A large-scale study compared mathematics courses that used student- and instructor-centered teaching. Women's confidence and interest increased in the student-centered courses but declined in the instructor-centered courses [19].

\section{METHODS}

The analysis presented here is part of the second phase of a multi-method study examining what influences faculty to try new teaching practices. The first phase consisted of interviews and focus groups, which informed the construction and dissemination of a survey in the second phase. Topical selections and findings from the survey reflect the qualitative data. A more extensive investigation into the results regarding faculty adoption are explored in [16].

\subsection{Survey Development}

In [2] and [3], we reported the results of the qualitative phase of the two part study, which used interviews, focus groups, and classroom observations with 66 U.S. CS faculty members at 36 postsecondary institutions. Purposive sampling was used to maximize the range of experiences of faculty, seeking diversity in research or teaching focus, tenure status, institutional focus, student body characteristics, highest degree offered, public/private funding, minority/majority serving status, and geographic location. We conducted one hour, semi-structured interviews, or focus groups, with participants and observed the classroom teaching of most $(n=55)$ to enhance our interpretation of the interviews. Data were transcribed and reviewed extensively by members of the research team to allow for emergent coding of the data, and we used keyword searches and targeted, thematic coding for hypothesis testing. Findings were then used, in conjunction with relevant theory and literature, to inform topics, content, and specific word choices in the survey.

\subsection{Survey Design}

The survey was designed and disseminated in accordance with best practices outlined in the tailored design method $[9,10]$ and other social science surveying methodology scholarship [1, 27]. To increase the accuracy of respondents' memories, the first survey item asked faculty to think of "a CS course you have taught in the past few years, preferably a course undergraduates take early in the major/minor," and write the course name or number in a text box. To further elicit grounded memories, the second survey item asked faculty to provide that course's enrollment. Asking people to reflect on their behavior over a set timeframe within a specific context is more likely to result in an accurate representation of behaviors than asking about "typical" behavior or general inclinations [10,27]. The contents of the first text box (the course name or number) were then piped into the next set of survey items, to increase the likelihood that respondents were continuing to think of one specific course as they responded to questions. Survey items then asked faculty to report the frequency with which they had used practices and tools in that specific class, using a 5-point ordinal scale: "never," "one class session," "some class sessions," "most class sessions," and "every class session." A "don't know" option was provided. 
In the last two sections of the survey, we also asked questions about respondents' organizational and occupational contexts, as well as personal demographics. Rather than asking respondents what type of institution they worked in, we stored responses to the survey invitation, which were sent out based on institutional type (explained in the next section) since faculty often work at multiple institutions. Incentive and survey data was stored in separate databases to protect confidentiality.

The survey went through several cycles of revision to incorporate feedback from CS faculty and doctoral students. A near-final version of the survey was piloted with additional faculty and Ph.D. students teaching introductory CS courses. The final survey was disseminated in the summer of 2017.

\subsection{Sampling and Respondent Profile}

The sample was developed from all U.S. postsecondary computer science departments that awarded at least one associate or bachelor's degree in 2015. We downloaded data from the National Center for Education Statistics Integrated Postsecondary Educational Data System (IPEDS [17]), selecting all U.S. public and not-for-profit private institutions that had awarded CS degrees in "computer science" or "computer and information sciences." We created separate download files for institutional categories (listed in Table 1). Because some institutions fit multiple categories, we assigned schools to only one group to avoid confusion. Then we searched online to identify one to four faculty members for each department who were shown as the instructor of record for a lower-division course. Email addresses were stored in separate "collector" files, enabling us to send targeted invites per category based on the evolving distribution of participants. The result was a sample stratified by institution types in the U.S.

We sent email invitations to 4,088 faculty, offering a $\$ 20$ Amazon gift card as a pre-incentive. ${ }^{1} \mathrm{We}$ followed up with reminders until the number of respondents was proportional to the number of institutions listed per category. For some categories, e.g., Historically Black Colleges and Universities (HBCUs), we continued to search for and invite more faculty until we had adequate representation.

The survey was completely anonymous. Although we collected email addresses to send gift cards and logged invitation acceptances to prevent double-sampling, the survey required respondents to click through the incentive request form to access the anonymized survey. Data from each form were stored in completely separate databases. Limited by funds and our promise of gift cards, we closed the survey when we reached 751 incentive claims. However, many faculty members chose not to request the gift card, resulting in 821 complete surveys. The overall response rate of individuals for this study is 20 percent.

When the incentive request form redirected to the actual survey, the collector name (i.e., institutional category) was retained, allowing us to do analysis by institution type. Although

${ }^{1}$ Pre-incentives have been shown in survey research studies to outperform postincentives. Invitation links took respondents to a page where they could request the incentive. Once they requested it, they were asked to follow another link to the survey itself. Information about who requested the incentives was stored in a completely separate database from the final survey results and we had no way of identifying respondents in the substantive survey. the exact number is unknown, based on opened invitations and incentive hits, we estimate that the data represents about 595 institutions. The number of participants for each institutional type is shown in Table 1. The proportions of respondents by institutional type are within 4 percent on average of those listed in IPEDS data for CS degree-granting institutions [17]. Underrepresented categories in the sample, two-year degree and Hispanic-Serving institutions, have sufficiently large sample sizes to be able to report significance levels for inferential statistics.

\section{Table 1: Final Sample Respondents by Institutional Type}

\begin{tabular}{lc}
\hline Institution Type & Number \\
\hline Two-year, Associate Degree Only Granting Institutions & 164 \\
Research Intensive/Extensive & 133 \\
Historically Black Colleges and Universities & 26 \\
Hispanic-Serving Institutions & 101 \\
Tribal Colleges & 5 \\
Small Colleges (Enrollments $<5,000$ Students) & 209 \\
Medium Colleges and Universities & 47 \\
Large Universities (Enrollments $>10,000)$ & 136 \\
\hline Total & $\mathbf{8 2 1}$ \\
\hline
\end{tabular}

\section{$4 \quad$ RESULTS}

\subsection{Frequency of Using Teaching Practices}

We asked faculty to report how often they used several teaching practices and tools the last time they had taught a specific course. These teaching practices are based on the content of interviews, as discussed in section 3.1. Error! Reference source not found. displays the results, which are ordered from "most used" to "least used." "Don't know/not applicable" responses are not shown in the table, but were used to help assess the relative use of each practice. ${ }^{2}$

Consistent with most studies of teaching in STEM, the most commonly selected and most frequently used practices were instructor-centered. "Presented content by lecturing" was by far the most commonly and frequently used practice: over 75 percent of respondents reported having lectured in most or all class sessions. Using whiteboards and chalkboards was also very common, perhaps reflecting that faculty work out problems in real time, express algorithms visually, etc. This could reflect student-centered teaching, if students use them, but in classroom observations mentioned in section 3.1, we found board work often consisted of faculty transmitting information to passive students-hence, we classified it as instructor-centered. Using slides, a clearer manifestation of instructor-centered practcices, were used in most or all class sessions by half of the sample and used in some class sessions by another 22 percent. Taken together, the frequencies of these three practices indicate that instructor-centered teaching practices are more widely and frequently used in CS higher education than the studentcentered practices included in our study.

\footnotetext{
2 "'Most used' to 'least used" was assessed by a scale based on the sum of weighted rankings for each practice, ranked and weighted according to how many faculty selected each response option and what practical interpretation each response option represented (e.g., "every class session" was weighted by $4 \mathrm{x}$ while "never" was weighted by $-1 \mathrm{x})$.
} 
Table 2: Reported Frequencies of Using Teaching Practices

\begin{tabular}{|c|c|c|c|c|c|c|}
\hline Teaching Practice & & $\begin{array}{c}\text { Every } \\
\text { class } \\
\text { session }\end{array}$ & $\begin{array}{c}\text { Most } \\
\text { class } \\
\text { sessions }\end{array}$ & $\begin{array}{c}\text { Some } \\
\text { class } \\
\text { sessions }\end{array}$ & $\begin{array}{c}\text { One } \\
\text { class } \\
\text { session }\end{array}$ & Never \\
\hline \multirow{2}{*}{$\begin{array}{l}\text { Presented content } \\
\text { by lecturing* }\end{array}$} & $\%$ & $39 \%$ & $38 \%$ & $20 \%$ & $1 \%$ & $2 \%$ \\
\hline & $\mathrm{N}$ & 310 & 307 & 159 & 9 & 19 \\
\hline \multirow{2}{*}{$\begin{array}{l}\text { Used whiteboards } \\
\text { or chalkboards* }\end{array}$} & $\%$ & $34 \%$ & $32 \%$ & $25 \%$ & $2 \%$ & $6 \%$ \\
\hline & $\mathrm{N}$ & 274 & 257 & 201 & 18 & 50 \\
\hline \multirow{2}{*}{$\begin{array}{l}\text { Used slide } \\
\text { presentations* }\end{array}$} & $\%$ & $26 \%$ & $24 \%$ & $22 \%$ & $6 \%$ & $22 \%$ \\
\hline & $\mathrm{N}$ & 208 & 192 & 179 & 48 & 174 \\
\hline \multirow{2}{*}{$\begin{array}{l}\text { Used examples } \\
\text { intended to } \\
\text { connect to } \\
\text { students' interests }\end{array}$} & $\%$ & $19 \%$ & $36 \%$ & $39 \%$ & $2 \%$ & $3 \%$ \\
\hline & $\mathrm{N}$ & 148 & 288 & 315 & 13 & 25 \\
\hline \multirow{2}{*}{$\begin{array}{l}\text { Led in-class } \\
\text { discussions }\end{array}$} & $\%$ & $12 \%$ & $26 \%$ & $42 \%$ & $5 \%$ & $14 \%$ \\
\hline & $\mathrm{N}$ & 99 & 206 & 335 & 40 & 113 \\
\hline \multirow{2}{*}{$\begin{array}{l}\text { Used recording of } \\
\text { your own lectures } \\
\text { for student use } \\
\text { outside of class* }\end{array}$} & $\%$ & $10 \%$ & $5 \%$ & $13 \%$ & $3 \%$ & $68 \%$ \\
\hline & $\mathrm{N}$ & 82 & 38 & 105 & 28 & 546 \\
\hline \multirow{2}{*}{$\begin{array}{l}\text { Used online } \\
\text { discussions }\end{array}$} & $\%$ & $9 \%$ & $10 \%$ & $24 \%$ & $3 \%$ & $53 \%$ \\
\hline & $\mathrm{N}$ & 74 & 79 & 192 & 25 & 421 \\
\hline \multirow{2}{*}{$\begin{array}{l}\text { Collected student } \\
\text { input in real time }\end{array}$} & $\%$ & $8 \%$ & $13 \%$ & $33 \%$ & $4 \%$ & $42 \%$ \\
\hline & $\mathrm{N}$ & 67 & 106 & 260 & 31 & 332 \\
\hline \multirow{2}{*}{$\begin{array}{l}\text { Flipped or inverted } \\
\text { the class }\end{array}$} & $\%$ & $6 \%$ & $8 \%$ & $25 \%$ & $7 \%$ & $49 \%$ \\
\hline & $\mathrm{N}$ & 47 & 66 & 198 & 58 & 395 \\
\hline \multirow{2}{*}{$\begin{array}{l}\text { Required students } \\
\text { to use Agile or pair } \\
\text { programming }\end{array}$} & $\%$ & $4 \%$ & $7 \%$ & $23 \%$ & $5 \%$ & $58 \%$ \\
\hline & $\mathrm{N}$ & 29 & 60 & 182 & 44 & 466 \\
\hline \multirow{2}{*}{$\begin{array}{l}\text { Used process- } \\
\text { oriented guided } \\
\text { inquiry learning } \\
\text { (POGIL) }\end{array}$} & $\%$ & $1 \%$ & $4 \%$ & $10 \%$ & $3 \%$ & $64 \%$ \\
\hline & $\mathrm{N}$ & 8 & 30 & 77 & 21 & 513 \\
\hline
\end{tabular}

However, similar to [12], results suggest that faculty often used a combination of instructor-centered and student-centered practices. Only three respondents reported using only instructorcentered practices and only five faculty relied solely on studentcentered practices. Instead, faculty typically reported using two or all three of the instructor-centered practices in conjunction with three or more student-centered practices.

Among the eight student-centered instructional techniques shown in the table, employing "examples intended to connect to students' lives and interests" was the most frequently used practice, with 55 percent of faculty using it in most or every class session. Nonetheless, 3 percent of respondents reported never using this practice, 2 percent used it only once, and 39 percent reported making content meaningful only in some class sessions. In other words, almost half the faculty (45 percent) do not use this technique regularly.

In-class discussions were also commonly used, clustering around "some" or "most class sessions." Other student-centered practices, however, were used less frequently. More than half of respondents reported never using online discussions. And despite the notoriety of certain practices in conferences and workshops, faculty rarely (or infrequently) used prescriptive student-centered instructional techniques, such as flipping the classroom, requiring students to learn through the Agile method or pair programming, using process-oriented guided inquiry learning (POGIL), and recording lectures as videos for later student use.

\subsection{Differences Across Variables}

In order to understand under what conditions faculty use certain practices, we conducted statistical analyses to find out whether there are differences in the usage of each practice by institutional type, tenure status, career duration, teaching load, gender, and race. Tests consisted of analyses of variance (ANOVAs), with appropriate post hoc tests depending on whether or not variances were equal between groups; MannWhitney $U$ tests, which are essentially t-tests for non-parametric data; Spearman's rho correlations, which are essentially Pearson's correlations for non-parametric data; and chi-squared tests. Because institution types can overlap, comparisons are only made between groups based on size, degree conferral, and populations served.

Overall, we found that usage of practices varies slightly by some variables, but effect sizes are very small. In the subsections below we briefly describe some of the more interesting results.

4.2.1. Differences by Institutional Types. Regarding the use of instructor-centered practices, we observed a few statistically significant differences between institutional types. However, the magnitude and effect sizes of these differences are slight.

Faculty at large institutions used both lecturing and slides slightly more frequently than faculty at small institutions (lecturing mean difference $[\Delta]=.45$ on the five-point ordinal scale, $P<.001$; slides $\Delta=.67, p<.001)$. Both effect sizes are small $\left(\eta^{2}=.05\right.$ and .04 , respectively), accounting for five percent or less of the variance. This difference may be a byproduct of the classes' enrollment sizes, which were larger by about 80 students on average for faculty at large institutions $(p=.001)$. Given the high level of overall use of lecturing and slides across all faculty, this difference amounts to using it extremely often versus very often, in practical terms.

Regarding the use of student-centered practices, faculty from two-year institutions used most of the student-centered practices slightly more frequently than other faculty, though those differences and their effect sizes are small. Both in-class and online discussions, relevant examples, and POGIL mean differences are between .44 and .22, with effect sizes accounting for less than 4 percent of the variance $\left(\eta^{2} \leq .04\right)$. However, twoyear faculty used Agile/pair programming less than four-year colleagues on average $\left(\Delta=-.25, \quad p=.035, \quad \eta^{2} \leq .01\right)$. Perhaps differences in department structure or culture could be at play, though further study would be necessary.

Faculty at minority-serving institutions had a higher average frequency than those at majority-serving institutions for using online discussions $\left(\Delta=.35, p=.005, \eta^{2} \leq .01\right)$ and POGIL $(\Delta=.28$, $\left.p=.004, \eta^{2} \leq .01\right)$, but again, these differences are slight in magnitude and effect size.

4.2.2. Differences by Tenure Status. We asked respondents to report whether they were non-tenure track, tenure $\operatorname{track}^{3}$, or tenured. Overall, very few differences were observed. Regarding instructor-centered practices, tenured faculty used slide

${ }^{3}$ By "tenure-track," we mean faculty who are in positions leading to tenured positions, but are not yet tenured. 
presentations slightly less often than both tenure track $(\Delta=-.61$, $p<.001)$ and non-tenure track faculty $(\Delta=-.65, p<.001)$. The effect size was very small $\left(\eta^{2}=.04\right)$. Speculatively, this relationship may relate to what level of course faculty teach (e.g., intro versus upper-division). The variability in how faculty reported the name or title of their courses in the survey question prevents us from exploring this hypothesis with our data, but no differences were observed in class sizes.

Regarding student-centered practices, tenured faculty used examples intended to connect to students' lives and interests less frequently than tenure-track faculty by .22 on the five-point ordinal scale $(p=.043)$ and faculty without a tenuring system by $.51(p<.001)$. The overall effect size was small $\left(\eta^{2}=.03\right)$.

4.2.3. Differences by Gender. Of the four identified instructorcentered practices, only lecturing differed statistically between men and women, with men having higher frequencies of using lectures to deliver content than women $\left(\Delta=.25, p=.001, \eta^{2}=.01\right)$. This difference was slight, amounting to one-quarter of an interval point; gender accounted for only one percent of the variance in lecturing.

Out of the seven student-centered practices, women used three with greater regularity than men: POGIL, flipping or inverting the class, and conducting online discussions. Of the three, flipped classrooms had the highest mean difference (at slightly over half an ordinal point), but even for this practice, gender only explained three percent of the variance in usage. POGIL and online discussions each had a mean difference less than .25 and an effect size of .01 .

\subsection{Faculty Explanations for Teaching Choices}

The final survey question was optional, stating, "We value your thoughts and opinions. If you have any additional comments or questions, or if you have comments about this survey, please write them here." Although we did not explicitly ask for explanations, many respondents gave accounts for their teaching choices.

Some faculty expressed concerns about students' negative judgments. For example, "I worry that making the students think and participate in class is harder for them than sitting and listening and they might not enjoy them as much, and give me lower evaluation scores, even if they are learning more effectively." This concern for course evaluations is consistent with some of our interview findings. Another respondent was also concerned with students' reactions, writing, "My college is pushing the flipped classroom approach far more than I think it should. Most of my students have expressed displeasure with this approach." Perhaps a more cavalier attitude is shown in this comment, "My school gives merit pay and a large percentage of it is based on student evaluations. I am currently receiving high student evaluations so there is very little personal reward for trying innovative teaching techniques."

Others expressed concern about student learning. Concerned that students would not learn without the lecture, a respondent wrote, "Our students simply will not read anything technical unless it is a requirement for completing an assignment or know there will be a quiz the next class period." Another expressed concern with making sure the required material was covered, writing, "There are just times where I would like to ensure material is covered."

Others use instructor-centered approaches because of large enrollments or heavy teaching loads. For example, "There are many innovating and effective ways to teach a class with up to 50 students. The challenge is how to effectively teach a class of 150 and 300 students" and, "Time is the biggest problem when you are teaching $20+$ hours a semester."

Other faculty provided justification for using studentcentered approaches, sometimes based on educational research literature, like this instructor: "Research has shown that when students are interacting and discussing a subject area they tend to learn better than in the traditional lecture setting." Others simply feel that they are less effective at engendering student learning using instructor-centered approaches. One respondent wrote, "I have taught in lecture halls and hate doing so, as I feel like I'm wasting everyone's time. I only teach in computer labs now, in groups of 40 students at a time, and intersperse lab and lecture." Some faculty have adopted student-centered practices in an attempt to retain certain types of students: "I wanted to improve retention of students in CS courses beyond intro, especially underrepresented groups and personalities that can be turned off by arrogant, socially-awkward, domineering students, of which there are often many in CS classes."

\section{DISCUSSION}

\subsection{Summary of Findings and Differences}

This study combines with [12] to build a clearer understanding of the frequency with which CS faculty use instructor- and student-centered teaching practices. Using a survey technique designed to spur respondents' recall of teaching in a recent lower-division course, we focused on specific teaching practices rather than more abstract, self-categorization of practice. Thanks to the funding for this study, we were able to more deliberately reach more institutional types.

Our findings confirm that CS faculty in the U.S. rely heavily on instructor-centered teaching approaches, especially lecturing and using slides. However, while more CS faculty tended to use instructor-centered teaching practices, and used them more frequently, they also tried out student-centered practices, at least on (what appears to be) and experimental basis.

Though we found few, and slight, differences among faculty types, some of them are of interest. For example, the observation that faculty at schools with small overall enrollments use lecture and slides less frequently than do faculty from other institutional types suggests that schools with a teaching mission may be slightly more successful at fostering student-centered teaching. Considering huge enrollment increases in the past several years in CS, we speculate that instructor-centered practices are rising.

Two-year school faculty reported a student-centered focus in a variety of teaching practices. Two-year schools have not been heavily studied in terms of typical teaching practices. This study shines some light on this issue. Faculty in two-year schools have special challenges, as students come in with very different levels of preparation and goals. For example, some students may not have qualified for a four-year institution, some simply want to sample courses and not seek degrees, and others are specifically 
focused on certifications for jobs. In addition, a large percentage of minority students and those who are first in family to attend college begin at two-year schools, potentially bringing diversity to the CS field-if they can be induced to stay.

Faculty at minority-serving institutions were more likely to use just two student-centered practices: online discussions, and, surprisingly, POGIL. However, since very few faculty overall used POGIL, this difference is likely not indicative of much except that POGIL has perhaps been marketed to MSIs more rigorously.

Junior faculty on the tenure track more frequently used examples intended to be personally meaningful to students than did tenured faculty, possibly related to the age of faculty or recency of their own student experience. Non-tenure track and not-yet-tenured faculty also used slides more often than tenured faculty, perhaps reflecting some flavor of "born digital" for a younger generation. In [12], it was reported that women were more likely to use student-centered practices and less likely to use instructor-centered practices than men. Our results suggest that the relationship is more complex, as we found only a very weak association between women and student-centered practices.

Faculty account for their teaching approaches in a number of ways. Faculty justifying the use of instructor-centered approaches wrote open-ended comments about negative judgments by students and student course evaluations, making sure students learned the material, large enrollments, and heavy teaching loads. Faculty justified using student-centered approaches based on research evidence, feelings of effectiveness, and to retain underrepresented students.

\subsection{Limitations of the Study}

In addition to unavoidable self-selection and response biases risks inherent to the sampling and survey design methods, there is a risk that respondents might interpret terms such as "lecturing" or "flipping the classroom" differently. Although we tried to describe each teaching practice clearly in the survey, misinterpretation by respondents or misclassification by us in terms of instructor- or student-centered are still possible. This is why we focused on less ambiguous practices (lecture and slides). In addition, some faculty may think they are using a particular practice but are only implementing part of it, possibly in a way that jeopardizes the effectiveness of the innovation [5]. Implementation fidelity is a particular issue for prescriptive innovations like POGIL and pair programming.

A potential solution for future studies would be to survey both students and faculty using descriptive language rather than formal titles. Connecting faculty perceptions about their teaching with student perceptions may help establish validity and better gauge the fidelity of implementation.

A major limitation of this study is that the bank of practices and tools used in the survey is far from comprehensive. A large number of student-centered practices have been developed over the last few decades. Many CS faculty use student- and instructor-centered approaches that we did not list in our survey; our selection process of using examples that emerged in interviews or that were notable examples we felt were common in the field may have led us to omit other, potentially more common practices. Other studies should expand this inventory, and preferably, establish longitudinal patterns of usage.

\section{CONCLUSION}

Despite the demonstrated and perceived value of studentcentered teaching approaches, it is unlikely that lecture and slides will die off in CS in the near future. Our results show that while most faculty lecture frequently, they also combine instructor-centered practices with student-centered practices in ways that make sense to them, such as leading in-class discussions and using examples that "connect to students' lives and interests." There is room for using more student-centered approaches, but currently most faculty are not only lecturing, and that is a good thing.

Faculty teach under a variety of conditions, including in situations where student evaluations are used to make nontrivial judgments about promotion, salary, and tenure. In such a case, it is understandable that faculty may stick to a safe path using practices that they perceive as what students expect [2]. The huge increases in CS enrollment as well as the limitations of the physical spaces where faculty teach are also likely to affect the practices faculty choose in classes. Those wishing to encourage better propagation of student-centered teaching in CS higher education should leverage the practices-and their motivationsthat faculty actually use, in ways that accommodate the constraints faculty face.

The SIGCSE community may want to consider approaches to increasing the use of student-centered practices beyond the community itself. That is, faculty who attend SIGCSE are probably more likely to hear about and talk about innovations in their teaching than their peers who have never attended SIGCSE, but instead use their travel funds for technical SIGS.

We close with a provocation to the SIGCSE community. Shulman [26] argues that disciplines have signature pedagogies, which are particular teaching approaches that are useful for showing and demonstrating concepts; assumptions about the best ways of teaching concepts; and a tacit moral dimension that describes what is valued by a profession. Instead of seeking to do away with what is apparently a signature pedagogy in CS (and therefore, heavily entrenched in CS education), perhaps educational development specialists should provide instruction on improving the content of lectures and the form with which they are delivered. Instead of advocating for taking the instructor off the stage, we can teach instructors to perform better on the stage-improving the form with which they present ideas, using whiteboards more effectively and interactively. Showing practical applications of computing and connecting with students' interests and real world concerns using analogies and metaphor can make content meaningful, engage students, and improve learning. Sages who refuse to give up the stage might be persuaded to at least begin to share it, which could be a good gateway to student-centered teaching.

\section{ACKNOWLEDGMENTS}

Thank you to our survey respondents, research assistants, and reviewers who improved this study at every turn. Thank you to the National Science Foundation for funding this study under award DUE \#1123332. 


\section{REFERENCES}

[1] Babbie, E.R. 1990. Survey research methods. Wadsworth Publishing Co.

[2] Barker, L. and Gruning, J. 2014. The Student Prompt: Student Feedback and Change in Teaching Practices in Postsecondary Computer Science. Proceedings of the 44th Annual Frontiers in Education Conference (Madrid, Spain, Oct. 2014), 1-8.

[3] Barker, L., Hovey, C.L. and Gruning, J. 2015. What Influences CS Faculty to Adopt Teaching Practices? Proceedings of the 46th ACM Technical Symposium on Computer Science Education (Kansas City, Missouri, March 4-7, 2015, 2015), 604-609.

[4] Bell, T., Cockburn, A., Mckenzie, B. and Vargo, J. 2001. Flexible Delivery Damaging to Learning? Lessons from the Canterbury Digital Lectures Project. (2001).

[5] Borrego, M., Cutler, S., Prince, M., Henderson, C. and Froyd, J.E. 2013. Fidelity of Implementation of Research-Based Instructional Strategies (RBIS) in Engineering Science Courses. Journal of Engineering Education 102, 3 (Jul. 2013), 394-425. DOI:https://doi.org/10.1002/jee.20020.

[6] Braxton, J.M., Doyle, W.R., Hartley, H.V., Hirschy, A.S., Jones, W.A. and McLendon, M.K. 2013. Rethinking college student retention. Jossey-Bass.

[7] Castells, M. 2009. The Rise of the Network Society: The Information Age: Economy, Society, and Culture Volume I. Wiley-Blackwell.

[8] Dancy, M. and Henderson, C. 2010. Pedagogical practices and instructional change of physics faculty. American fournal of Physics. 78, 10 (Oct. 2010), 1056-1063. DOI:https://doi.org/10.1119/1.3446763.

[9] Dillman, D.A. 2007. Mail and Internet Surveys: The Tailored Design Method. Wiley.

[10] Dillman, D.A., Smyth, J.D. and Christian, L.M. 2014. Internet, phone, mail, and mixed-mode surveys: the tailored design method. Wiley.

[11] Freeman, S., Eddy, S.L., McDonough, M., Smith, M.K., Okoroafor, N., Jordt, H. and Wenderoth, M.P. 2014. Active learning increases student performance in science, engineering, and mathematics. Proceedings of the National Academy of Sciences. 111, 23 (Jun. 2014), 8410-8415. DOI:https://doi.org/10.1073/pnas.1319030111.

[12] Grissom, S., Fitzgerald, S., McCauley, R. and Murphy, L. 2017. Exposed! CS Faculty Caught Lecturing in Public: A Survey of Instructional Practices. Proceedings of the 2017 ACM SIGCSE Technical Symposium on Computer Science Education (New York, NY, USA, 2017), 261-266.

[13] Hake, R. 1998. Interactive-engagement versus traditional methods: A six thousand student survey of mechanics test data for introductory physics students. American fournal of Physics. 66, 1 (1998), 64-73.

[14] Henderson, C. and Dancy, M.H. 2007. Barriers to the use of research-based instructional strategies: The influence of both individual and situational characteristics. Physical Review Special Topics - Physics Education Research 3, 2 (Sep. 2007 ), 020102. DOI:https://doi.org/10.1103/PhysRevSTPER.3.020102.
[15] Henderson, C. and Dancy, M.H. 2009. Impact of physics education research on the teaching of introductory quantitative physics in the United States. Physical Review Special Topics - Physics Education Research. 5, 2 (Dec. 2009), 020107. DOI:https://doi.org/10.1103/PhysRevSTPER.5.020107.

[16] Hovey, C.L., Barker, L. and Nagy, V. forthcoming. Survey Results on Why CS Faculty Adopt New Teaching Practices. Proceedings of the 50th ACM Technical Symposium on Computer Science Education (Minneapolis, Minnesota, forthcoming).

[17] Integrated Postsecondary Education Data System: 2016. http://nces.ed.gov/ipeds/.

[18] Kaput, K. 2018. Evidence for Student-Centered Learning. Technical Report \#ED581111. Education Evolving.

[19] Laursen, S.L., Hassi, M.-L., Kogan, M. and Weston, T.J. 2014. Benefits for Women and Men of Inquiry-Based Learning in College Mathematics: A Multi-Institution Study. Fournal for Research in Mathematics Education. 45, 4 (2014), 406-418. DOI:https://doi.org/10.5951/jresematheduc.45.4.0406.

[20] National Academy of Engineering 2004. The Engineer of 2020: Visions of Engineering in the New Century. National Academies Press.

[21] National Academy of Sciences (US), National Academy of Engineering (US), and Institute of Medicine (US) Committee on Underrepresented Groups and the Expansion of the Science and Engineering Workforce Pipeline 2011. Expanding Underrepresented Minority Participation: America's Science and Technology Talent at the Crossroads. National Academies Press.

[22] Obi-Okogbuo, J. 2015. Science, Technology, and Globalization: A ReAppraisal in the Philosophy of Science and Technology. European Scientific fournal. 11, 14 (May 2015).

[23] Pascarella, E.T. and Terenzini, P.T. 2005. How college affects students Volume 2: A third decade of research. Jossey-Bass.

[24] Porter, L., Guzdial, M., McDowell, C. and Simon, B. 2013. Success in Introductory Programming: What Works? Communications of the ACM. 56, 8 (Aug. 2013), 34-36. DOI:https://doi.org/10.1145/2492007.2492020.

[25] Russell, J., VanHorne, S., Ward, A.S., Bettis, E.A., Sipola, M., Colombo, M. and Rocheford, M.K. 2016. Large Lecture Transformation: Adopting Evidence-Based Practices to Increase Student Engagement and Performance in an Introductory Science Course. Fournal of Geoscience Education; Bellingham. 64, 1 (Feb. 2016), 37-51. DOI:https://doi.org/10.5408/15-084.1.

[26] Shulman, L.S. 2005. Signature pedagogies in the professions. Daedalus. 134 3 (Jun. 2005), 52-59. DOI:https://doi.org/10.1162/0011526054622015.

[27] Tourangeau, R. 2000. The psychology of survey response. Cambridge University Press.

[28] Walter, E.M., Henderson, C.R., Beach, A.L. and Williams, C.T. 2016 Introducing the Postsecondary Instructional Practices Survey (PIPS): A Concise, Interdisciplinary, and Easy-to-Score Survey. CBE-Life Sciences Education. 15, 4 (Dec. 2016), ar53. DOI:https://doi.org/10.1187/cbe.15-090193. 